\title{
The Effects of Marble Dust on the Rheological and Mechanical Properties of Shotcrete
}

\author{
Mostafa Shaaban \\ Civil Engineering Department \\ Giza Higher Institute for Engineering and Technology \\ Giza, Egypt \\ mostafa.shaaban@gei.edu.eg
}

\begin{abstract}
Recycling industrial waste materials has become an environmental and economic necessity. The utilization of these materials to develop concrete contributes not only to their disposal, but also to the preservation of the environment. This study attempted to evaluate the properties of sprayed concrete with Marble Dust (MD) as partial replacement of concrete components. For this purpose two series of concrete mixtures were prepared: the first series included six mixtures containing MD as cement replacement with percentages of $5 \%, 10 \%, 15 \%$, $\mathbf{2 0} \%, \mathbf{2 5 \%}$, and $30 \%$ by weight, the second series included six mixtures containing $5 \%, 10 \%, 15 \%, 20 \%, 25 \%$, and $30 \%$ of $\mathrm{MD}$ as replacement for sand. Also, conventional concrete mixture with $100 \%$ cement and $100 \%$ sand was produced as control mixture. Rheological and mechanical properties as pumpability, build-up thickness, rebound percentage, adhesion strength, and compressive and tensile strength were studied. In general, the results indicate that use of MD improves shotcreting as an application and shotcrete's performance.
\end{abstract}

Keywords-sprayed concrete; marble dust; spraybility; strength; rebound ratio; shotcrete

\section{INTRODUCTION}

Shotcrete, also referred to as sprayed concrete or spraycrete, is defined as concrete shooted through a hose at high velocity and pneumatically projected onto a surface [1] or as concrete produced with basic mix and projected pneumatically from nozzle into place to produce a dense homogeneous layer [2]. EFNARC defines it as a concrete mix projected pneumatically into a surface to produce a homogeneous and dense mass [3]. This concrete is used for repairs of concrete buildings, underground concrete reservoirs, lining of tunnels, and rapid concrete construction. In order to produce shotcrete, two steps have to be carried out: the fresh concrete must first be pumped, and then shot, so the ideal shotcrete mix should have suitable pumpability, and sprayability, in addition to proper strength. Pumpability (i.e. the mobility and stability of concrete under pressure) is measured by standard tests such as the slump test. It is recommended that concrete should possess slump higher than $50 \mathrm{~mm}$ [4]. Sprayability incorporates parameters such as the ability of shotcrete to stick to itself (cohesion) without segregation, to adhere to a surface (adhesion), and to be buildup in thick sections and concrete ricochets off the impacted surface (rebound). When concerning strength, shotcrete should have a compressive strength higher than $30 \mathrm{MPa}$, whereas, for permanent tunnel lining, a compressive strength of at least $40 \mathrm{MPa}$ is required [5]. Shotcrete should have bond or adhesion strength of 0.5 to $1.0 \mathrm{MPa}$ [3] in order to stick to the sprayed surface. Marble Dust (MD) is a solid waste material generated from marble processing and can be used as a cement or fine aggregate replacement material in concrete admixures. Authors in $[6,7]$ studied the effect of sand replacement with different levels of MD on concrete properties. They observed that the replacement of sand with $15 \% \mathrm{MD}$ results in compressive strength increment. Authors in [8] examined the concrete properties containing $0 \%, 5 \%, 10 \%$, and $20 \%$ of MD as cement substitution. Attractive outcomes were achieved for substitution proportions of up to $10 \%$. Authors in [9] reported that the replacement cement by MD in a percentage up to $5 \%$ could be secure, without unfavorable impact on the bond properties of cement in concrete. Authors in [10] reported that concrete mechanical properties rise with $15 \%$ MD substitution. Authors in [11] investigated the properties of fresh and hardened concrete containing $0,5,10,15$, and $20 \%$ of tile and marble powders. The results indicate that using $2.5 \%$ marble powder $+2.5 \%$ tile powder led to increase the compressive and tensile strengths by $8.9 \%$ and $8.3 \%$ respectively. Authors in [12] studied the effects of sand replacement with $0 \%, 25 \%$, $50 \%, 75 \%$, and $100 \%$ of MP on the mechanical properties of concrete. They reported that substituting sand with $50 \% \mathrm{MP}$ increased the compressive and flexural strengths by $13.52 \%$ and $35.54 \%$ respectively.

Although many studies have examined the utilization of $\mathrm{MD}$ as a replacement material for sand or cement, however none focused on the effects of MD on the rheological and mechanical properties of shotcrete, properties as pumpability, build-up thickness, rebound percentage compressive strength, tensile strength, and adhesion or bond strength. So, this study aims to study the MD effects on the aforementioned properties of fresh and hardened shotcrete.

\section{RESEARCH METHODOLOGY}

\section{A. Materials Used}

Natural dolomite with 2.65 specific gravity and $10 \mathrm{~mm}$ nominal size was used as coarse aggregate in all concrete mixtures, while natural sand was used as fine aggregate. The 
fine and coarse aggregates satisfied the ASTM C33/C33-M [13] specifications. CEMI-42.5N Ordinary Portland cement complying with ASTM C150/C150-M [14] was used in all mixtures with different proportions. Locally available MD with a specific gravity of 2.27 and particle size finer than $80 \mu \mathrm{m}$ which was prepared according to [15] was used as cement replacement, while MD with particle size ranging between 0.075 to $2 \mathrm{~mm}$ (Figure 1) was used as sand replacement, in six mixtures with percentages of $5 \%, 10 \%, 15 \%, 20 \%, 25 \%$, and $30 \%$ for each case. Potable water complying with ASTM C1602/C1602M-18 [16] was used in concrete mixing and curing. ViscoCrete SC that meets ASTM C494 Type F [17] was used as a superplasticizer in $1 \%$ percentage.

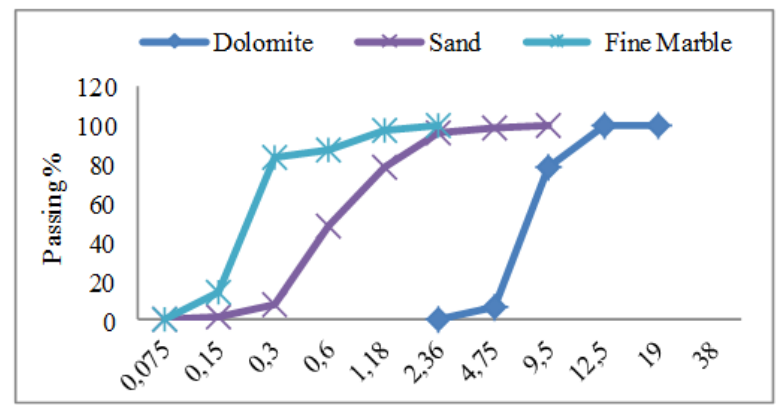

Fig. 1. Particle size distribution for coarse and fine aggregates.

\section{B. Mixing and Specimen Preparation}

The material proportions were estimated based on ACI 506.4R-94 [18]. The quantities of concrete ingredients are given in Table I. The materials were mixed in an electric mixer, then concrete specimens were prepared for testing the hardened properties as follows: Plywood molds of $1000 \mathrm{~mm} \times 1000 \mathrm{~mm}$ were used. The molds were positioned vertically, and fresh concrete was sprayed in $150 \mathrm{~mm}$ thickness under the same conditions. The samples were cured until extraction. The tests of compressive strength were conducted according to [19] on drilled cores taken from the prepared test panel. The samples' diameter was at least $50 \mathrm{~mm}$ and the height/diameter ratio ranged between 1.0 to 2.0 . The samples required to perform tensile and adhesion tests were cored in accordance with [20].

TABLE I. CONCRETE MIX PROPORTIONS $\left(\mathrm{Kg} / \mathrm{m}^{3}\right)$

\begin{tabular}{|c|c|c|c|c|c|c|c|}
\hline \multirow{2}{*}{ Replacem.\% } & \multirow{2}{*}{ OPC } & \multirow{2}{*}{ MD } & \multirow{2}{*}{ Water } & \multirow{2}{*}{ C. Agg. } & \multicolumn{2}{|c|}{ F. Agg. } & \multirow{2}{*}{ HRWR } \\
\hline & & & & & Sand & MD & \\
\hline \multicolumn{8}{|c|}{ Control mix (0\% MD) } \\
\hline $0 \%$ & 400 & 0 & 160 & 1080 & 600 & 0 & 4 \\
\hline \multicolumn{8}{|c|}{ Replacement of cement with MD } \\
\hline $5 \%$ & 380 & 20 & 160 & 1080 & 600 & 0 & 4 \\
\hline $10 \%$ & 360 & 40 & 160 & 1080 & 600 & 0 & 4 \\
\hline $15 \%$ & 340 & 60 & 160 & 1080 & 600 & 0 & 4 \\
\hline $20 \%$ & 320 & 80 & 160 & 1080 & 600 & 0 & 4 \\
\hline $25 \%$ & 300 & 100 & 160 & 1080 & 600 & 0 & 4 \\
\hline $30 \%$ & 280 & 120 & 160 & 1080 & 600 & 0 & 4 \\
\hline \multicolumn{8}{|c|}{ Replacement of sand with MD } \\
\hline $5 \%$ & 400 & 0 & 160 & 1080 & 570 & 30 & 4 \\
\hline $10 \%$ & 400 & 0 & 160 & 1080 & 540 & 60 & 4 \\
\hline $15 \%$ & 400 & 0 & 160 & 1080 & 510 & 90 & 4 \\
\hline $20 \%$ & 400 & 0 & 160 & 1080 & 480 & 120 & 4 \\
\hline $25 \%$ & 400 & 0 & 160 & 1080 & 450 & 150 & 4 \\
\hline $30 \%$ & 400 & 0 & 160 & 1080 & 420 & 180 & 4 \\
\hline
\end{tabular}

\section{Testing Procedure}

\section{1) Rheological Properties}

The rheological properties or flow properties of shotcrete such as pumpability (i.e. mobility and stability under pressure), build-up thickness, and rebound percentage were measured according to the corresponding standards as illustrated below.

- Pumpability: This characteristic was measured by the slump test. The slump test was conducted according to ASTM C143 [21] and the test results were compared with the recommendations of ACI 304.2R-17 [4].

- Build-up thickness: To measure build-up thickness, the test procedure presented in JSCE-F 563-2005 [22] was followed.

- Rebound percentage: To measure rebound percentage, the test procedure of JSCE-F 563-2005 [22] was followed.

\section{2) Mechanical Properties}

- Compressive and tensile strength tests were conducted according to ASTM C 1604/C1604M [23] at 7 and 28 days.

- The adhesion strength test was performed according to ASTM C882 [24] at 28 days.

\section{RESULTS AND DISCUSSION}

\section{A. Slump}

The influence of MD on concrete slump at different replacement percentages is shown in Figure 2. In general, the value of slump decreases as the MD level increases whether it is used as a replacement to cement or sand. The results indicate that the slump of mixtures containing MD as a replacement for cement is less than that of the $0 \% \mathrm{MD}$ mixture. This decrease in slump value is caused by the reduced flowability due to the increase of the concrete viscosity resulting from the use of MD [25]. Also, the results in Figure 2 show that the use of MD as a sand replacement results in a decrease of slump up to $40 \%$, in comparison with the control mixture. This behavior may be related to the fineness of MD which is higher than that of cement. As the particle fineness increases, the concrete water demand increases and consequently reduces concrete slump. Studies have shown that the slump of the concrete mixtures is negatively influenced by the MD substitution and this effect occurs at greater substitution levels (beyond 15\%) [26].

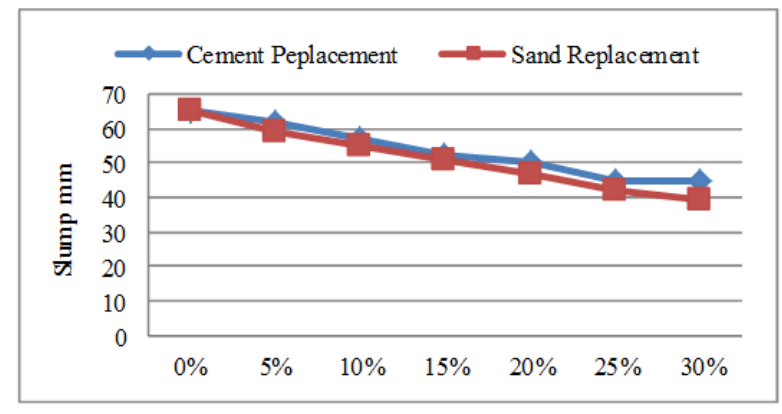

Fig. 2. Slump values of concrete mixtures. 


\section{B. Build-Up Thickness}

Figure 3 shows the variation in the build-up thickness of concrete mixtures comparing to the build-up thickness of the control mix. The results indicate that the use of MD as a cement replacement material results in a slightly decrease of the buildup thickness ranging between $1.3 \%$ and $4.59 \%$, with the maximum increase obtained for $30 \%$ MD. Also, Figure 3 indicates that the mixtures containing $\mathrm{MD}$ as a sand replacement have values of build-up thickness higher than the build-up thickness of the control mixt, due to that MD particles are finer than sand particles and the cohesive nature of MD is higher than sand's [27].

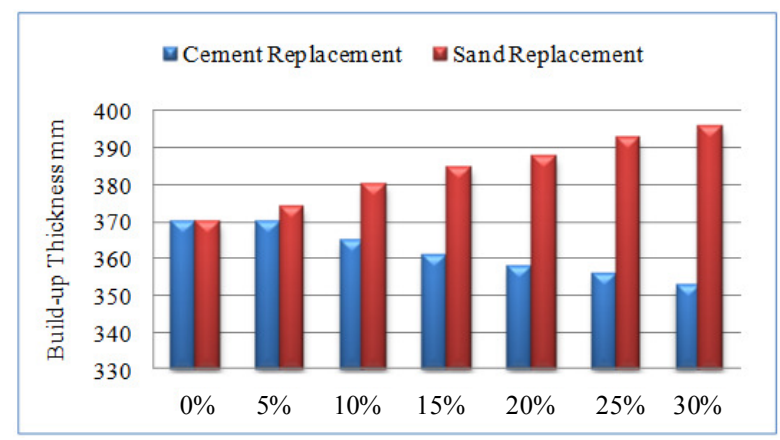

Fig. 3. Build-up thickness of concrete mixtures.

\section{Rebound Percentage}

Figure 4 presents the results obtained for different mixtures shot under the same conditions (spray distance and angle). Increase of the rebound percentage due to the replacement of cement were observed, while mixtures containing MD as sand replacement had rebound percentages lower than that of the control mix. These results can be explained by the role that cohesion plays in rebound reduction. The MD is more cohesive than natural sand, so consequently, increasing MD against the percentage of sand results in a lower rebound amount [27].

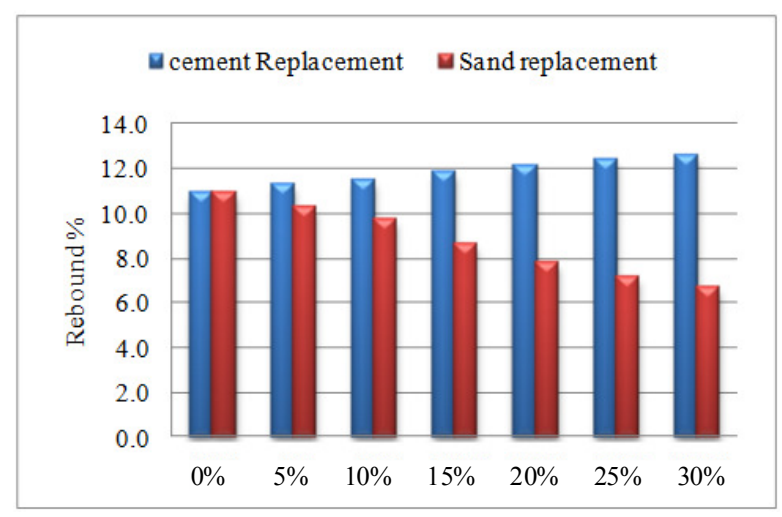

Fig. 4. Rebound percentage of concrete mixtures.

\section{Adhesion Strength}

Figure 5 shows the results of the adhesion strength test for all mixtures at the age of 28 days. The results clarify that replacement of cement with MD causes decrease in the adhesion strength. On the other hand, the use of MD as sand replacement led to adhesion strength increase. For the same MD replacement levels, the decrease of adhesion strength in the case of cement replacement is higher than the obtained increase in the case of sand replacement.

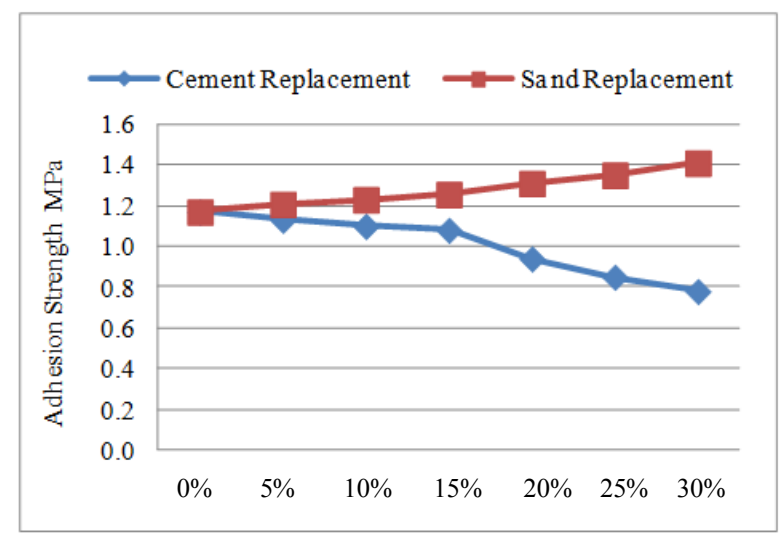

Fig. 5. Adhesion strength of concrete mixtures at 28 days.

\section{E. Compressive Strength}

Figure 6 demonstrates the effect of MD as cement or sand replacement on 7- and 28-day compressive strength tests. At the age of 7 days, the mixtures containing MD as cement replacement at all replacement levels exhibit decreased compressive strength in comparison with the control mix $(0 \%$ MD) with percentages ranging between $5.4 \%$ for $5 \% \mathrm{MD}$ and $23.4 \%$ for $30 \% \mathrm{MD}$. The results at the age of 28 days follow the same behavior but with smaller decrease, ranging between $4.9 \%$ for replacement level of 5\% MD and 23\% for 30\% MD. It is noticeable that the replacement of cement with MD led to a decrease in compressive strength. This decrease occurs because MD does not have pozzolanic properties [28-30]. The obtained test results at the age of 7 days of mixtures containing MD as sand replacement show increased compressive strength in comparison with the control mix $(0 \% \mathrm{MD})$. Also, the results at 28 days indicate that the mixtures with $\mathrm{MD}$ as sand replacement have increased compressive strength. In general, it can be reported that the partial replacement of sand with MD causes a significant rise in compressive strength, a result of the filler effect of MD. This result is agreement with the findings in $[26,31]$.

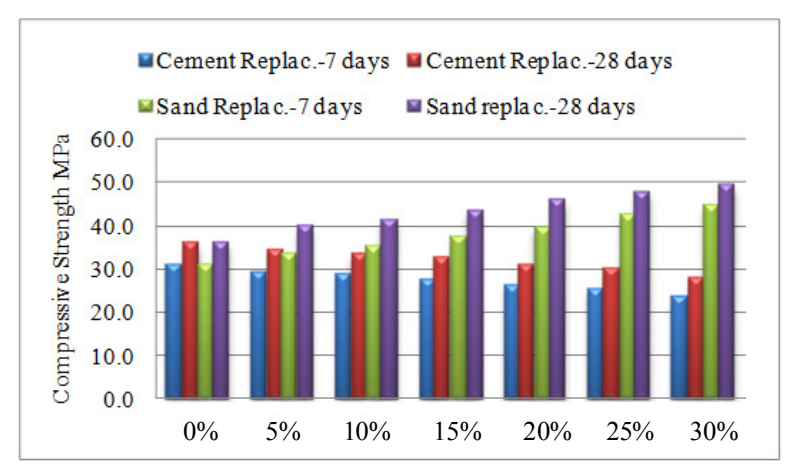

Fig. 6. Compressive strength at 7 and 28 days. 


\section{F. Tensile Strength}

Figure 7 shows the results of tensile strength tests of all concrete mixes at 7 and 28 days. Tensile strength at 7 days clarifies that the use of MD as cement replacement causes a decrease in tensile strength ranging between $11.3 \%$ and $29.3 \%$. The results of 28 days indicate that the use of MD as a cement replacement results in decrease of the tensile strength between $4.8 \%$ and $23 \%$. The results at the age of 7 days show that the strength of concrete mixtures with MD as sand replacement is higher increases by $7.2 \%-45 \%$. At 28 days, the tensile strength increases by $11 \%-37.2 \%$.

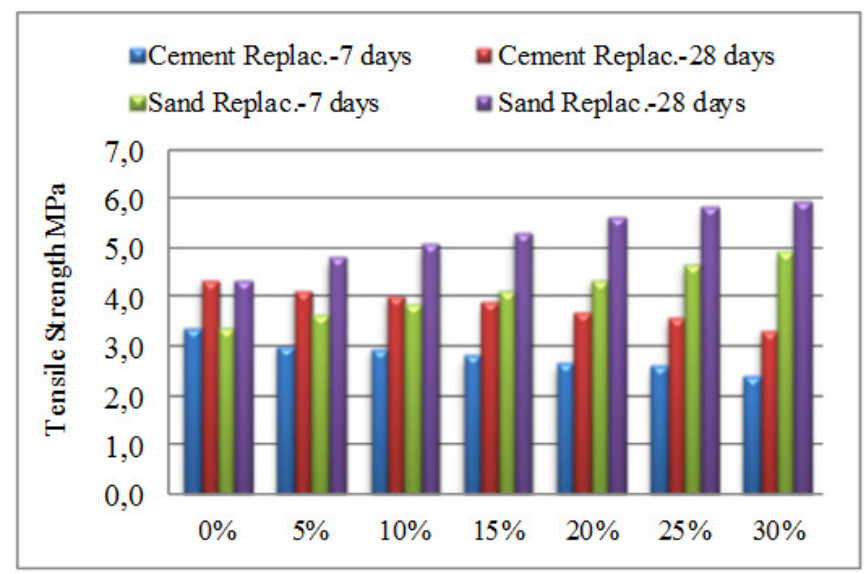

Fig. 7. Tensile strength at 7 and 28 days.

\section{CONCLUSIONS}

Based on the experimental results, the next conclusions can be drawn:

- Concrete mixtures containing $\mathrm{MD}$ as cement or sand replacement with percentages from $5 \%$ to $30 \%$ have slump values lower than the control mixture $(0 \% \mathrm{MD})$, but still higher than $50 \mathrm{~mm}$, which means that these mixtures fulfill the shotcrete requirements reported in [4].

- The use of MD as sand replacement with a percentage of $5 \%$ up to $30 \%$ has a positive effect on the rebound percentage of shotcrete. All mixtures have rebound percentages less than the control mix, while using MD as cement replacement at any percentage led to a slight increase of the rebound percentage.

- All concrete mixtures with $5 \%$ to $30 \% \mathrm{MD}$ as cement replacement have build-up thickness less than the build-up thickness of the control mix (370mm). Mixtures with MD as sand replacement have build-up thickness higher than the build-up thickness of the control mix.

- The compressive strength of the mixtures containing MD as cement replacement at the age of 28 days is less than that of the control mix but still higher than $30 \mathrm{MPa}$ (with the exclusion of $30 \%$ replacement) which meets the shotcrete requirements [5]. All mixtures containing $\mathrm{MD}$ as sand replacement have compressive strength higher than that of the control mix and more than 40MPa so these mixtures are suitable for permanent tunnel lining, where compressive strength of at least $40 \mathrm{MPa}$ is required [5].

- The adhesion strength of mixtures containing MD as sand replacement is higher than the adhesion strength of the control mixture, while the adhesion strength of mixtures containing MD as cement replacement is less than that of the control mixture.

Concluding, a mixture containing 5\% MD as cement replacement appears to be most suitable to be used as shotcrete.

\section{REFERENCES}

[1] ACI 506R, Guide to Shotcrete. Farmington Hills, MI: American Concrete Institute, 2016.

[2] BS EN 14487-1:2005 - Sprayed concrete. Definitions, specifications and conformity. London, UK: British Standards Institution, 2006.

[3] European specification for sprayed concrete. Farnham, UK: EFNARC, 1996.

[4] 304.2R-96: Placing Concrete by Pumping Methods (Reapproved 2008). Farmington Hills, MI: American Concrete Institute, 1996.

[5] ACI 506.5R-09: Guide for Specifying Underground Shotcrete. Farmington Hills, MI: American Concrete Institute, 2009.

[6] R. S. Kushwah, I. C. Sharma, and P. B. L. Chaurasia, "Utilization of marble slurry in cement concrete replacing fine aggregate," American Journal of Engineering Research, vol. 4, no. 1, pp. 55-58, 2015.

[7] F. Gameiro, J. de Brito, and D. Correia da Silva, "Durability performance of structural concrete containing fine aggregates from waste generated by marble quarrying industry," Engineering Structures, vol. 59, pp. 654-662, Feb. 2014, doi: 10.1016/j.engstruct.2013.11.026.

[8] R. Rodrigues, J. de Brito, and M. Sardinha, "Mechanical properties of structural concrete containing very fine aggregates from marble cutting sludge," Construction and Building Materials, vol. 77, pp. 349-356, Feb. 2015, doi: 10.1016/j.conbuildmat.2014.12.104.

[9] H. A. El-Sayed, A. B. Farag, A. M. Kandeel, A. A. Younes, and M. M. Yousef, "Characteristics of the marble processing powder waste at Shaq El-Thoaban industrial area, Egypt, and its suitability for cement manufacture," HBRC Journal, vol. 14, no. 2, pp. 171-179, Aug. 2018, doi: 10.1016/j.hbrcj.2016.06.002.

[10] M. Singh, A. Srivastava, and D. Bhunia, "An investigation on effect of partial replacement of cement by waste marble slurry," Construction and Building Materials, vol. 134, pp. 471-488, Mar. 2017, doi: 10.1016/j.conbuildmat.2016.12.155.

[11] N. Bheel, K. A. Kalhoro, T. A. Memon, Z. U. Z. Lashari, M. A. Soomro, and U. A. Memon, "Use of Marble Powder and Tile Powder as Cementitious Materials in Concrete," Engineering, Technology \& Applied Science Research, vol. 10, no. 2, pp. 5448-5451, Apr. 2020.

[12] M. J. Memon, A. A. Jhatial, Z. A. Rid, T. A. Rind, and A. R. Sandhu, "Marble Powder As Fine Aggregates in Concrete," Engineering, Technology \& Applied Science Research, vol. 9, no. 3, pp. 4105-4107, Jun. 2019.

[13] ASTM C33 / C33M - 18: Standard Specification for Concrete Aggregates. West Conshohocken, PA: ASTM International, 2018.

[14] ASTM C150 / C150M - 19a: Standard Specification for Portland Cement. West Conshohocken, PA: ASTM International, 2019.

[15] N. Toubal Seghir, M. Mellas, Ł. Sadowski, A. Krolicka, and A. Żak, "The Effect of Curing Conditions on the Properties of Cement-Based Composites Blended with Waste Marble Dust," JOM, vol. 71, no. 3, pp. 1002-1015, Mar. 2019, doi: 10.1007/s1 1837-018-3254-9.

[16] ASTM C1602 / C1602M - 06: Standard Specification for Mixing Water Used in the Production of Hydraulic Cement Concrete. West Conshohocken, PA: ASTM International, 2006.

[17] ASTM C494 / C494M-15, Standard Specification for Chemical Admixtures for Concrete. West Conshohocken, PA: ASTM International, 2015. 
[18] ACI 506.4R-94: Guide for the Evaluation of Shotcrete. Farmington Hills, MI: American Concrete Institute, 1994.

[19] EN 4012: Concrete - Determination of compressive strength of test specimens. EN, 2006.

[20] EN 7034: European Standard for Sprayed concrete, Testing concrete Cored specimens - Taking, examining and testing in compression. EN, 2006.

[21] ASTM C143 / C143M - 20: Standard Test Method for Slump of Hydraulic-Cement Concrete. West Conshohocken, PA: ASTM International, 2006.

[22] JSCE-F 563-2005: Test Method for Rebound Percentage of Sprayed Concrete (Mortar). Japan: JSCE, 2005.

[23] ASTM C1604 / C1604M - 05(2019): Standard Test Method for Obtaining and Testing Drilled Cores of Shotcrete. West Conshohocken, PA: ASTM International, 2019.

[24] ASTM C882 / C882M - 20: Standard Test Method for Bond Strength of Epoxy-Resin Systems Used With Concrete By Slant Shear. West Conshohocken, PA: ASTM International, 2005.

[25] N. Roussel, "Correlation between Yield Stress and Slump: Comparison between Numerical Simulations and Concrete Rheometers Results," Materials and Structures, vol. 39, no. 4, Jun. 2006, Art. no. 501, doi: 10.1617/s11527-005-9035-2.

[26] A. A. Aliabdo, A. E. M. Abd Elmoaty, and E. M. Auda, "Re-use of waste marble dust in the production of cement and concrete," Construction and Building Materials, vol. 50, pp. 28-41, Jan. 2014, doi: 10.1016/j.conbuildmat.2013.09.005.

[27] Department of Army: U. S. Army Corps of Engineers, Standard Practice for Shotcrete. BiblioGov, 2013.

[28] M. V. Sekhar Reddy, K. Ashalatha, M. Madhuri, and P. Sumalatha, "Effect of Various Replacement Levels of Waste Marble Dust In Place of Fine Aggregate to Study the Fresh and Hardened Properties of Concrete," International Journal of Engineering Research and Applications, vol. 5, no. 12, pp. 73-77, Jan. 2015.

[29] K. Vardhan, R. Siddique, and S. Goyal, "Strength, permeation and micro-structural characteristics of concrete incorporating waste marble," Construction and Building Materials, vol. 203, pp. 45-55, Apr. 2019, doi: 10.1016/j.conbuildmat.2019.01.079.

[30] A. K. Saha, P. K. Sarker, and S. Majhi, "Effect of elevated temperatures on concrete incorporating ferronickel slag as fine aggregate," Fire and Materials, vol. 43, no. 1, pp. 8-21, 2019, doi: 10.1002/fam.2664.

[31] P. A. Shirule, A. Rahman, and R. D. Gupta, "Partial replacement of cement with marble dust powder," International Journal of Advanced Engineering Research and Studies, vol. 1, no. 3, pp. 175-177, Apr. 2012. 